\title{
Editorial: Advances in Seismic Performance and Risk Estimation of Precast Concrete Buildings
}

\author{
Andrea Belleri ${ }^{1 *}$, Bruno Dal Lago ${ }^{2}$ and Hugo Rodrigues ${ }^{3}$ \\ ${ }^{1}$ Department of Engineering and Applied Sciences, University of Bergamo, Dalmine, Italy, ${ }^{2}$ Department of Theoretical and Applied \\ Sciences, Università degli Studi dell'Insubria, Varese, Italy, ${ }^{3}$ Civil Engineering Department, University of Aveiro, Aveiro, Portugal
}

Keywords: precast concrete, seismic risk, connections, joints, structural retrofit

Editorial on the Research Topic

Advances in Seismic Performance and Risk Estimation of Precast Concrete Buildings

\section{INTRODUCTION}

The design of precast buildings during past years was typically carried out without considering the complex seismic interaction between elements, both structural and non-structural, due to the peculiar nature of precast connections and overall building behaviour. This fact was recently and dramatically shown by several earthquakes. The seismic safety of the building stock is a requirement of modern societies and remains a concern in seismic prone areas. Recently, a growing research interest has been observed on the seismic behaviour of reinforced concrete (RC) precast elements and connection systems, mainly considering current code-conforming solutions. However, the knowledge gap is far from being filled. The Engineering community is currently facing the following challenges to reduce the seismic vulnerability and risk associated with precast structures: 1) refinement and harmonization of design criteria for new buildings and new precast technologies, 2) seismic assessment and risk analysis of the existing building stock, and 3) setting and employing robust retrofit solutions.

The present research topic contributes to these goals by gathering a diverse set of recent studies, which provide original papers and review articles addressing the current challenges related to the seismic performance of precast structures. A total of 10 papers authored by 29 experts of the field have been finally selected to integrate the present issue, encompassing the objectives described above.

The topics addressed in the papers are from several fields across civil engineering, including: an overview of the recent advances carried out by one among the most active research groups in the field; four papers related with the different challenges in the design and in the experimental and numerical assessment of different beam-column connections, including dissipative, moment resisting, and dowel; two contributions regarding the vulnerability assessment of precast industrial buildings with cladding panels employing novel connection devices; a paper considering unbonded post-tensioned precast walls and their modelling challenges; a paper discussing the modelling assumptions and its influence in the seismic risk assessment of industrial precast structures; a paper dealing with the effectiveness of retrofitting solutions for post-earthquake interventions in industrial precast buildings.

Belleri A, Dal Lago B and Rodrigues H (2021) Editorial: Advances in Seismic

\section{PAPERS IN THE COLLECTION}

The first paper of the collection (Zoubek et al.) reviews and comments the outcome of a long-lasting research activity carried out at the University of Ljubljana concerning the seismic behaviour of 
precast structures, focusing on a new capacity model of beamcolumn dowel connections, new insights into the cyclic behaviour and design procedures of fastening systems of concrete cladding panels, a methodology for seismic fragility analysis of RC precast buildings, and back-up (strengthening) system to prevent the falling of cladding panels in case of a strong earthquake.

The second paper of the collection (Muciaccia) contributes to filling the gap between the lack of agreement regarding the applicability of Eurocode 2 rules for fastening in concrete to the design cases related to dowel connections, specifically concerning the role of the edge reinforcement and the effectiveness of multiple reinforcement layers in the proximity of the steel bar.

The third paper of the collection (Bressanelli et al.) presents a novel dissipative beam-to-column crescent moon connection device to be employed for the retrofit of existing precast industrial buildings, encompassing the descriptions of experimental tests, numerical modelling, and design criteria related to the single device and the retrofitted precast building.

The fourth paper of the collection (Magliulo et al.) presents a study aimed at assessing the seismic behaviour of a single-story $\mathrm{RC}$ precast building in terms of global collapse implementing two different models of the beam-to-column connection, a simplified and a refined one, through non-linear static and dynamic analyses of a single-story RC precast building.

The fifth paper of the collection (Atalay and Ozden) presents and discuss a new moment resisting precast concrete beamcolumn connection detail with post-tensioning bolts, made out of high yield strength steel, comparing its moment capacity, stiffness, energy dissipation and the residual displacement performance with traditional solutions.

The sixth paper of the collection (De Stefani and Scotta) aims to evaluate the efficiency of dissipative panel-to-structure and roof connections in precast buildings. The results of the analysis highlight a better performance of buildings including such connections, particularly when a rigid roof diaphragm is provided.

The seventh paper of the collection (Gajera et al.) presents the seismic assessment of precast frame structures employing pendulum, cantilever, and rocking cladding connection systems with a probabilistic approach based on the results of static and multi-stripe dynamic non-linear analyses. The results indicate a low vulnerability of well-detailed modern precast industrial frame structures provided with decoupling cladding connections.

The eighth paper of the collection (Kalliontzis and Nazari) discusses and compares numerical and analytical modelling techniques for rocking walls precast panels, where dry wall-tofoundation connections employing unbonded post-tensioning tendons provide a re-centring capability even for strong earthquakes.

The ninth paper of the collection (Bressanelli et al.) aims at evaluating the influence of modelling assumptions in the seismic risk assessment of industrial precast buildings, in particular assessing the modelling influence of mass, overhead crane, beam-to-column and roof-to-beam connections, and cladding systems.

The 10th paper of the collection (Minghini and Tullini) aims at evaluating the effectiveness of real retrofit interventions on industrial buildings struck by the Emilia earthquakes, addressing in particular the force transfer mechanisms between the existing structure and the new strengthening system.

The editorial team is sure that the papers reflect significant contributions to the research and development in the various topics addressed. We hope that readers will find all articles of the research topic useful and exciting and that the articles will stimulate further research activities in the area of seismic performance of precast concrete structures.

\section{AUTHOR CONTRIBUTIONS}

$\mathrm{AB}, \mathrm{BL}$, and HR conceived and edited the Research Topic. All authors have made a substantial, direct and intellectual contribution to the work, and approved it for publication.

\section{ACKNOWLEDGMENTS}

$\mathrm{AB}$ and $\mathrm{BDL}$ handled manuscripts with the collaboration of Prof. Massimo Latour and Prof. Arturo Tena-Colunga, who are kindly acknowledged. The interest of all the authors and the contribution of all the reviewers is greatly acknowledged.

Conflict of Interest: The authors declare that the research was conducted in the absence of any commercial or financial relationships that could be construed as a potential conflict of interest.

Publisher's Note: All claims expressed in this article are solely those of the authors and do not necessarily represent those of their affiliated organizations, or those of the publisher, the editors and the reviewers. Any product that may be evaluated in this article, or claim that may be made by its manufacturer, is not guaranteed or endorsed by the publisher.

Copyright ( 2021 Belleri, Dal Lago and Rodrigues. This is an open-access article distributed under the terms of the Creative Commons Attribution License (CC BY). The use, distribution or reproduction in other forums is permitted, provided the original author(s) and the copyright owner(s) are credited and that the original publication in this journal is cited, in accordance with accepted academic practice. No use, distribution or reproduction is permitted which does not comply with these terms. 